\title{
Research on the Vertical Management Mode of Five-Year Majors in Colleges and Universities
}

\author{
Wenjie Liu \\ School of Civil Engineering and Architecture \\ Wuhan University of Technology \\ Wuhan, China
}

\begin{abstract}
At present, there are some five-year majors in Chinese universities, which usually have distinctive professional features and a longer training period. Therefore, there are many contradictions and differences between these five-year majors and the existing four-year majors. This paper discusses the working mechanism of the vertical management mode of fiveyear majors, it works as a bridge to connect all the necessary aspects, as an entity to have a full map of student cultivation throughout the five academic years, also as a platform builder to give a more colorful and wider platform. As an effective mode of student management, it helps to tackle the contradictions among different majors and improves managers' working capability and work efficiency as a whole. Under this management mode, the scattered management objects are integrated to improve the working efficiency and professional degree of managers. In addition, the management mode helps stundents with their selfdevelopment as it meets the needs of students' psychological development, and it adapt to the current development trend and requirements of education management.
\end{abstract}

Keywords—colleges and universities; five-year majors; vertical management mode

\section{INTRODUCTION}

Student management is a combination of students ideological and political education, daily life and behavior management, psychological statement analysis and counseling, as well as the employment guidance, and the academic counseling. In view of the number of college students, the characteristics of student groups are varied, and the focus of work in different grades is different. In the meantime, the work of the student manager faces serious tasks and challenges with tremendous change.

The horizontal management mode is the most common one, the manager is in charge of all the students from five to six majors in a same grade. It enables the manager to deal with all the students of a grade, however, majors are close but not similar, The job of the manager is fundamental and especially when the number of students is large, it is even limited to basic day-to-day management. Meanwhile, after the four-year students are graduated, the management of a small amount of the rest five-year students is difficult and cumbersome. In the meantime, fragmentary work objects restrict the improvement and development of managers' professional improvement and autonomy, and the construction of management platform is affected. On the other hand, the horizontal management mode of joint management of fiveyear and four-year majors has practical difficulties and continuity problems. This management mode helps to focus on solving short-term problems in practice but ignores students' self-education and peer education [1]

In view of the above limitation of the present working mode and due to the fact that there are many five-year majors. It is necessary and feasible to explore a new vertical management mode that is different from the traditional ones. That is, managers are responsible for the students of the same majors in different grades, especifically for the two five-year majors, including students from three adjacent classes and fifteen classes from freshman to fifth grade, to offer a more systematic counseling and management mode. This vertical management mode is not commonly seen and is different from the student management mode in most of the colleges and universities.

\section{Working Method OF Vertical Management Mode}

\section{A. How does the vertical management mode work}

One article mentions that in the vertical management mode, the four grades are an entity from the first and the graducating grades [2]. For instance, in the department of Civil Engineering and Archtitecure of Wuhan University of Technology, there are two five-year majors: architecture and urban and rural planning There are currently six undergraduate majors and nearly 2,500 undergraduate students. Two of them, as mentioned above, are five-year majors, and their contents, learning styles and professional categories are distinctly different from the other four four-year majors. In terms of the number of students, there are about 500 students in the fifth-grade architecture and urbanrural planning, which is equivalent to the number of new students enrolled in the other four majors. In consequence, among the managers, the department tries to manage all fiveyear maojor students by one manager, while the other managers are still in charge of the other four majors horizontally. Therefore, each manager is responsible for the same number of students, and if fully implemented vertically, it solves the problem of fifth grade students. In this vertical management mode, managers have more things to deal with and their responsibilities and roles simultaneously increase and enrich. 


\section{B. Working as a bridge to connect all the necessary aspects}

Managers' work in the traditional mode is relatively independent, and they have few opportunities to communicate with teachers or in other words, in such a concentrated way of one or two specific majors. These situations require managers to play an important role in education and guidance with high efficiency and quality. How to maximize the working enthusiasm of managers and ensure the quality and quantity is an important aspect that needs to be paid attention to when formulating the management mode [3]. The manager takes the responsibility as the bridge and actively communicates with the class headteacher, professional teachers and students. Every year when new students enter the school, the college employs a group of topping professional teachers as class headteachers. Then the manager selects and optimizes according to the understanding of the teachers and the teachers' wishes. This will strengthen the relationship between the manager and the class headteacher, and it is easy to have full control of the students and it provides a better communication method between the manager and the teachers from the major [4]. During the period of study, due to different majors, there are obvious differences in the curriculum. The manager only manages two majors with a high degree of relevance, the manager has a clear understanding of the curriculum, examination and practice requirements of the major he/she is in charge of, and knows well about the learning situation, class atmosphere and learning style of the students of the major. In addition, the close communication with professional teachers mentioned above can provide effective guidance and help for students in case of academic confusion or even academic difficulties.

\section{Working as an entity to have a full map of student cultivation throughout the five academic years}

The management of the manager includes career planning, evaluation and research, and awards and loans. Job responsibilities require manager fully grasp the various situations of the classes they are taking and to carry out threedimensional counseling. After adopting the vertical management mode, managers are more targeted and instructive in the career planning, because the learning characteristics and focus of each stage of the students are familiar, the manager can organize the creative characteristics of the profession. Professional career guidance activities. At the same time, it is also possible to combine student management with the management of party branches, to establish a vertical party branch, provide in-depth guidance, and to supervise the whole working process. It is worth noting that the vertically established party branch effectively solved the problem that the student party members' mobility due to graduation. In addition, the manager can give full play to the leading role of party members and activists to promote the class and even professional construction. At the same time, according to the different levels of work in different grades, students have different psychology; the manager can carry out special activities, and conduct the counseling and guidance deeply. Third, under vertical management, managers can more effectively cultivate students' multi-faceted personal abilities, track the growth process of students from the entrance of freshmen to the fifth year of graduation, and form an integrated counseling system.

TABLE I shows the specific targets and tasks for each grade from the first year to the fifth year, these targets closely relate to the development needs for each stage throughout the whole five academic years.

TABLE I. TARGETS AND TASKS OF FIVE GRADES

\begin{tabular}{|c|c|c|c|c|c|}
\hline Grade & Academic study & Activity & Target & Personal development \\
\hline First year & Fundamental courses & Senior guidance & Adapt to the university & Career acknowledgment & Cultural and sport activities \\
\hline Second year & Major basic courses & Inter-grades activities & Balanced development & Study instruction & Social practice \\
\hline Third year & Major developing courses & Academic activities & Deepened professional study & Study instruction & Academic competition \\
\hline Fourth year & Major key courses & Academic activities & Deepened professional study & Setting a goal & Academic competition \\
\hline Fifth year & Integrated courses & Graduation activities & Choosing a career & Career planning instruction & Field work \\
\hline
\end{tabular}

As the chart indicates, the vertical management in the fiveyear academic program enables the manager to arrange his or her work as an entity and have full knowledge of focus and prioritization of each grade.

\section{Working as a platform builder to give a more colorful and wider platform}

On the basis that manager can treat his or her work as an entity from first to the fifth year of one or no more than two majors. It is possible for the manager to build platforms within and between schools to provide students with opportunities to exchange learning and practice.

For one hand, the manager can conduct exchanges between old and new students in the five grades in which they are responsible, including fifteen classes, and carry out cross-grade pairing activities. As a traditional activity, senior students will give free instruction on the painting test to the new students every September. The painting test is crucial for their stay or leave and the new students become less anxious and nervous, they can get a better result in the test with a calm and clearheaded condition. When students take part in the academic competition or research projects senior students directly teach the experience to the lower grades in the course of the curriculum, the manager organizes the guidance and cultivates an interest in the profession from the lower grades. Senior students lead and guide lower grade students to participate in research projects, academic competitions or social practice, so that professional activities can develop in the lower grades and develop the habit of research and innovation.

For the other, managers can build professional promotion, academic exchanges, social awards and other platforms for 
their majors by inviting experts and senior practitioners to conduct professional salons, lectures and employment guidance hence to enhance the professionalism of management and to improve the efficiency of counseling.

\section{ADVANTAGES AND DISADVANTAGES OF THE VERTICAL MANAGEMENT MODE}

As mentioned above, vertical management mode can work as a bridge to connect all the necessary aspects, it can work as an entity to have a full map of student cultivation throughout the five academic years and it also works as a platform builder to give a more colorful and wider platform. Although there are many benefits, there are still difficulties in overall personnel allocation, practical operation and communication with other superior departments. The specific analysis is as follows.

\section{A. Advantages of the vertical management mode}

First, the vertical management mode guarantees the stability of managers. A full-time manager and (occasionally, when needed) a part-time manager can ensure the professionalism of the manager's work and ensures that the student is managed by the same manager within five years. This solves the problem that the fifth-grade students are not responsible in the horizontal management mode.

Second, vertical management mode can promote resource integration and unified coordination. In contrast with the traditional working mode, when adopting the vertical management mode, the manager needs to have a professional background or he or she has worked in the profession for many years. They can combine with the professional situation in the specific work, which is conducive to the development of the manager himself, and the manager can provide counseling that is more professional to the students in charge.

Third, exploring the innovative vertical management mode can help students develop self-education and self-management skills. An useful exploration of the vertical maganement mode is a favorable complement to the improvement of the existing management mode in colleges and universities, and it builds a platform for the realization of students' self-education [1]. With the progress of society and the development of science and technology, the talent training mode and discipline construction of colleges and universities are constantly being adjusted and improved to meet the needs of society. Under the new situation of social and economic development, the tendency of cultivating college students' self-study, selfmanagement and active participation in management is gradually strengthened. It is meaningful and necessary to explore a set of management modes that can stimulate students' enthusiasm and improve their learning efficiency under the existing student management modes. In the vertical management mode, senior students can actively participate in junior students' academic guidance, professional adaptation, class construction and characteristic activities, and fully fulfill their role as managers. Junior students can benefit from the close and diverse communication activities with professional teachers, head teachers and senior students, so as to develop a career plan suitable for them as early as possible, and clarify their graduation destination and job intention. In addition, students can turn their knowledge into real productivity by participating in various professional lectures and competitions. As the saying goes, "it is better to teach someone to fish than to give him a fish".

Last but not the least, managers can also realize selfimprovement and self-education in the vertical management mode. The workload of managers managing five different grades at the same time is much larger than that of horizontal management mode. In order to meet the different characteristics and needs of each grade, managers need to specify and implement different activity development plans and training programs. Moreover, the physiological and psychological state of students in each grade is not consistent. Compared with the horizontal management mode, it can improve the professional ability of managers in a short time.

\section{B. Several shortcomings and difficulties that should not be overlooked}

It is undeniable that vertical management mode also has shortcomings that need to be improved and faced.

The manager is responsible for the daily affairs of all students in the five grades. It also manages the freshman yearold graduates and is responsible for the fifth-grade graduates and three non-graduate grades at the same time. In this way, the manager's energy input in the student's work doubled even tripled and the task is large, the content is complicated and trivial.

Meanwhile, in the vertical management mode, when the manager communicates with the superior department, there will often be the problem of identity duplication and overlapping work. For example, when assigning work tasks at the beginning of the school year, the superior department will hold work assignment meetings for the management of freshmen and graduates respectively. When freshmen begin military training, managers will be required to devote most of their time and energy to freshmen. At this time, there will be lack of responsibility for senior students' management.

\section{CONCLUSION}

In summary, it is feasible and effective to implement a vertical management mode for some five-year majors when there are inconsistencies in the number of professional academic years under the college. While solving the management difficulties of the fifth grade, the vertical management mode can also have greater freedom and activity space in student management, and the manager's own ties and bridges are more obvious. The vertical management mode improves managers' working capability and work efficiency as a whole. Under this management mode, the scattered management objects are integrated to improve the working efficiency and professional degree of managers. In addition, the management mode helps stundents with their selfdevelopment as it meets the needs of students' psychological development, and it adapt to the current development trend and requirements of education management. Therefore, how to improve the vertical management mode so as to better adapt to the needs of student management is worth further consideration and research. 


\section{REFERENCES}

[1] Cheng Jie. Analysis on the "Vertical Management among Grades" in Student Management [J]. Scientific Era:2013(4) (In Chinese)

[2] Huang Xiaomei. Explore the Vertical Management of Medical School Classes[J].Science and Education Management, 2012 (5):4-50 (In Chinese)
[3] Zhang Guohong. Exploration on the Management Mode of College Student Management in the New Situation [J]. Journal of South China University of Technology, 2008 (1):78-80(In Chinese)

[4] Li Yanni. A Probe into the Vertical Management Mode of University Managers[J]. Asia Pacific Education, 2015(7):259, 231 (In Chinese) 